\title{
History of Infection Prior to Hematopoietic Stem Cell Transplant in the Recipient as a Risk Factor to Develop Acute Graft versus Host Disease
}

\author{
Alberto Olaya-Vargas ${ }^{1}$, Iván Castorena-Villa ${ }^{2}$, Martin Pérez-García1, \\ Gerardo Lopéz-Hernández ${ }^{1}$, Nideshda Ramírez-Uribe ${ }^{1}$, Haydeé Salazar-Rosales ${ }^{1}$ \\ ${ }^{1}$ Hematopoietic Stem Cell Transplant and Cell Therapy Program, National Institute of Pediatrics (INP), Mexico City, México \\ ${ }^{2}$ Hematopoietic Stem Cell Transplantand Cell TherapyProgram, Hospital Infantil de México Federico Gomez, Instituto Nacional \\ de Salud, México City, México \\ Email: ^alberto.olaya@yahoo.com.mx
}

How to cite this paper: Olaya-Vargas, A., Castorena-Villa, I., Pérez-García, M., Lopéz-Hernández, G., Ramírez-Uribe, N. and Salazar-Rosales, H. (2019) History of Infection Prior to Hematopoietic Stem Cell Transplant in the Recipient as a Risk Factor to Develop Acute Graft versus Host Disease. Journal of Cancer Therapy, 10, 327-335. https://doi.org/10.4236/jct.2019.104026

Received: March 1, 2019

Accepted: April 25, 2019

Published: April 28, 2019

Copyright $\odot 2019$ by author(s) and Scientific Research Publishing Inc. This work is licensed under the Creative Commons Attribution International License (CC BY 4.0).

http://creativecommons.org/licenses/by/4.0/

\begin{abstract}
Background: Acute graft-versus-host disease (aGVHD) is the most frequent and severe complication after allogeneic hematopoietic stem cell transplantation (HSCT). Objective: To determine if a history of prior infection in the allogeneic HSTC recipient is a risk factor to develop aGVHD. Methods: A retrospective cohort study based on data collected from the Department of Hematopoietic Stem Cell Transplantation at the Instituto Nacional de Pediatría (INP) from January 1998 to December 2016 was performed to identify if prior infection was a predictive risk factor for aGVHD. Results: 27 patients developed aGVHD (36.4\%). Median time to aGVHD presentation was 82 days ( 9 to 273 days). Most patients developed grade III aGVHD. Following the multivariate analysis peripheral blood $>$ bone marrow (OR 12.3; p < $0.001)$, cell dose $>8.3 \times 10^{6} / \mathrm{kg}$ (OR 7.1; $\left.\mathrm{p}=0.05\right)$, peripheral blood (OR: 11.4; $\mathrm{p}<0.001$ ), infection 3 months prior to allogeneic transplant (OR: 4.5; $\mathrm{p}<$ 0.03 ) and CMV infection in the recipient (OR: 4.68; $\mathrm{p}<0.03$ ) were significant. Conclusions: Either bacterial infection or CMV infection in the recipient was significant risk factor within the aGVHD recipients; it is important to consider these factors for patients that are going to receive an allogeneic HSCT.
\end{abstract}

\section{Keywords}

Allogeneic HSCT, Complications, Acute GVHD, HSCT Infections 


\section{Introduction}

Acute graft-versus-host disease (aGVHD) is the most frequent and severe complication after allogeneic hematopoietic stem cell transplantation (HSCT) [1]. Its incidence has been reported from $30 \%-80 \%$; the range of presentation is due to different risk factors within each patient. Previous history of infection in the allogeneic HSCT host activates the immune response and could be an independent risk factor to induce aGVHD.

Jaing et al., recently published information that links CMV infection as a risk factor for the development of aGVHD grades III and IV; on the other hand, Sano et al., reported that blood stream infection is also a risk factor for the development of aGVHD according to a analysis performed retrospectively in patients who had systemic infections in the first 30 days post-transplant [1] [2] [3].

Our objective was to determine if a history of prior infection in the allogeneic HSTC recipient is a risk factor to develop aGVHD.

\section{Materials and Method}

\subsection{Eligibility of Patients}

This is a retrospective cohort study based on data collected from the allogenic transplant performed at the Department of Hematopoietic Stem Cell Transplantation at the Instituto Nacional de Pediatría (INP) registered in a database, from January 1998 to December 2016. We identified 144 patients in the study period, of which 115 patients were eligible for the study because they received an allogeneic transplant, of these 115 cases, 41 patients were excluded due to that they did not achieve the graft for the reasons that are specified in the results section, leaving 74 patients for the final analysis.

\subsection{Classification by Degrees of aGVHD}

For the purpose of the study aGVHD was staged using the scores by Glucksberg in 1974, and then modified at the Keystone Conference in 1994. When diagnosis was uncertain a biopsy was obtained and diagnosis was confirmed by a pathologist.

\subsection{Study Variables and Definitions}

The main variables that were the objective of the study were: infections prior to the allogeneic HSCT was defined as the presentation of any infection 3 months prior to the procedure or history of cytomegalovirus (CMV) infection, confirmed by serology(antigens) or CMV viral load by real time polymerase chain reaction (RT-PCR) (positive: $>1000$ copies $/ \mathrm{mL}$ ).

Other variables analyzed were several classic risk factors for the development of aGVHD as the type of progenitor cell source defined by the site of obtaining hematopoietic progenitor cells (peripheral blood, bone marrow, umbilical cord blood), a high cellular dose defined as a dose $>8 \times 10^{6} / \mathrm{kg}$ of receptor weight, type of donor defined as related or unrelated and compatibility defined as HLA 
100\% compatible or haploidentical [4] [5].

A myeloablative conditioning regimen was applied for most patients except for haploidentical transplants that received a reduced intensity conditioning regimen.

The prophylactic regimen for aGVHD included the combination of cyclosporine plus methotrexate for all cases. For patients that developed aGVHD the regimen followed the guideline recommendations continuing immunosuppression with first-line methylprednisolone. For patients unresponsive to steroids, either cyclosporine or mofetil mycophenolate or mTOR inhibitors or anti-TNF antibodies were administered, taking into account the main organ affected [4] [5].

\subsection{Statistic Analysis}

Univariate analysis was performed to estimate the frequency of aGVHD presentation for each known risk factor. Relative risk was calculated within the studied risk factors. Chi-square and Fisher's test were applied to evaluate the statistical significance ( $\mathrm{p}$-values $<0.05$ were considered significant). For multivariable analyses (logistic regression), variables with parameter estimates with a p-value $\leq 0.05$ in the univariate analyses were included. Statistical evaluation was carried out using the version 15 of SPSS.

\section{Results}

\subsection{Characteristics of Patients}

A total of 144 transplants were performed during the study period, the transplant indications were predominantly hematologic malignancies (47.92\%), followed by solid tumors (20.14\%), primary immunodeficiency diseases $(18.75 \%)$, bone marrow failure $(8.33 \%)$, inherited metabolic diseases $(4.17 \%)$ and other diseases $(0.69 \%)$. Allogeneic HSCT corresponded to the majority of procedures $(115,80 \%)$.

The allogeneic HSCT indications were predominantly: hematologic malignancies $(60 \%)$, primary immunodeficiency disorders $(23.4 \%)$, bone marrow failure syndrome (10.4\%), inherited metabolic diseases (5.2\%), and other diseases $(0.84 \%)$. Mean age of the patients was 7.4 years (range: 0.4 to 18.7 years)

From the overall allogeneic HSCT 41 were excluded for the final analysis (34.7\%): 16 on account of primary graft failure, 12 caused by patient death during the period of aplasia, 8 for incomplete data, and 5 lost to follow-up.

The most common source of hematopoietic stem cells (HSC) was umbilical cord blood (48.8\%), followed by peripherical blood from HLA matched donor (33.9\%), bone marrow (7.8\%), haploidentical peripherical blood (3.4\%), and haploidentical peripherical blood plus umbilical cord blood (1.7\%) (Figure 1).

\subsection{Univariate and Multivariate Analysis}

Peripheral blood represents the highest risk factor for the development of aGVHD and in its comparison with bone marrow with the values of (OR 12.3 


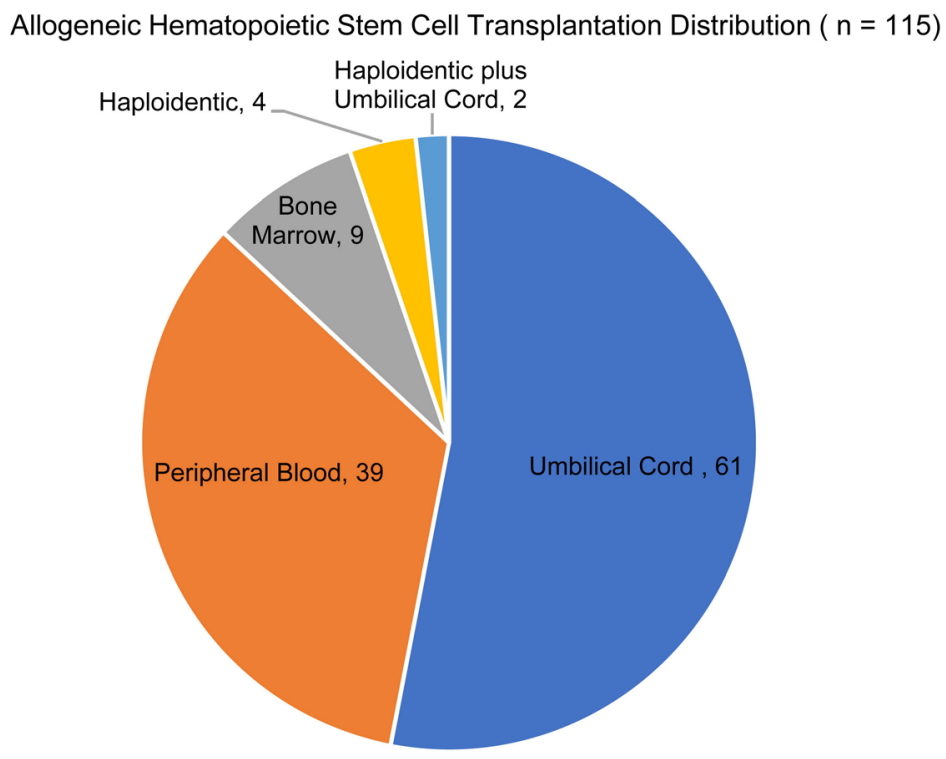

Figure 1. Allogeneic hematopoietic stem cell transplantation distribution $(n=115)$.

$\mathrm{p}<0.001$ and $6.2 \mathrm{p}<0.001$ respectively) higher, however, it was possible to confirm the objective of the in the univariate analysis, CMV infections in the recipient $(\mathrm{OR} 4.11 \mathrm{p}<0.03)$ had significant value, whereas infections in the 3 months previous to allogeneic transplantation were significant in the multivariate analysis (OR $4.5 \mathrm{p}<00.3)$. that the CMV infection was repeated with a significant result $(4.68 \mathrm{p}<0.03)$ (Table 1$)$. Other classic risk factors already referred to in the literature, such as the high cellular dose and the female and male recipient donor, were of significant value in our analysis.

It also draws attention, that umbilical cord blood was significant $(0.15 \mathrm{p}<$ 0.001 ) as a protective factor to reduce the development of aGVHD.

The final analysis included 74 patients, of which 27 developed aGVHD (36.4\%). Median time to aGVHD presentation was 82 days ( 9 to 273 days). Most patients developed grade III aGVHD, followed by grade II, IV and I (Figure 2).

The affected organs were: single presentation (skin 3.7\%, and gastrointestinal 7.4\%), double presentation skin and gastrointestinal (7.4\%), and triple presentation (skin, liver, gastrointestinal 74\%). Most patients with allogeneic HSCT were male, still, most of the patients that developed aGVHD were female. Further aGVHD patient characteristics are summarized in Table 2.

Eight patients with aGVHD died (29.6\%): 3 deaths were caused directly by aGVHD 3 (37.5\%), and 5 (62.5\%) were secondarily caused by severe infections following the allogeneic HSCT (Table 3).

\section{Discussion}

Over time, several risk factors have been reported for the development of aGVHD, the frequency of presentation is variable and depends on the characteristics of the group analyzed. One of the important points is that our analysis shows that the incidence of aGVHD in our institution is $31 \%$, that is within the 
Table 1. Univariate analysis adjusted by risk factor.

\begin{tabular}{|c|c|c|c|c|}
\hline \multicolumn{5}{|c|}{ Univariate analysis adjusted by risk factor } \\
\hline Risk Factor & $\begin{array}{l}\text { Patients with aGVHD } \\
\text { and risk factor }\end{array}$ & OR & $95 \%$ CI & p-value \\
\hline Peripheral blood & 23 & 6.25 & $2.39-16.28$ & 0.001 \\
\hline Bone marrow & 1 & 0.9 & $0.90-9.04$ & 0.7 \\
\hline umbilical cord & 3 & 0.15 & $0.45-0.53$ & 0.001 \\
\hline Total body irradiation & 10 & 1.96 & $0.76-5.03$ & 0.12 \\
\hline $\begin{array}{l}\text { Infection } 3 \text { months prior to } \\
\text { allogeneic transplant }\end{array}$ & 8 & 2.4 & $0.84-6.78$ & 0.84 \\
\hline HLA-matched unrelated & 1 & 1.1 & $0.20-6.06$ & 0.64 \\
\hline HLA-non-matched unrelated & 4 & 1.66 & $0.44-6.19$ & 0.32 \\
\hline Donor/recipient Female/male & 9 & 2.58 & $0.94-7.10$ & 0.05 \\
\hline $\begin{array}{l}\text { Bacteremia within the first } 7 \text { days } \\
\text { post-transplant, } \mathrm{n}\end{array}$ & 12 & 1.38 & $0.57-3.35$ & 0.3 \\
\hline $\mathrm{CMV}$ infection in the recipient & 4 & 4.11 & $0.85-19.68$ & 0.03 \\
\hline $\mathrm{PB}>\mathrm{BM}$ & 20 & 12.3 & $4.46-33.92$ & 0.001 \\
\hline Cell dose $>8.3 \times 10^{6} / \mathrm{kg}$ & 3 & 7.1 & $1.09-46.24$ & 0.05 \\
\hline
\end{tabular}

Table 2. Acute GVHD patient characteristics.

\begin{tabular}{|c|c|c|c|}
\hline \multirow[t]{2}{*}{ HSC Source } & $\begin{array}{l}\text { Peripheral } \\
\text { Blood }\end{array}$ & $\begin{array}{l}\text { Umbilical } \\
\text { Cord }\end{array}$ & $\begin{array}{l}\text { Bone } \\
\text { Marrow }\end{array}$ \\
\hline & No. & No. & No. $\%$ \\
\hline Patients & 85.18 & 11.11 & 3.7 \\
\hline Age, y.m (range) & $9.6(0.5-18.7)$ & $5.3(0.4-13.2)$ & 17.4 \\
\hline Sex, Male/female & $16 / 7$ & 42737 & $0 / 1$ \\
\hline \multicolumn{4}{|c|}{ Underlying disease, $\mathrm{n}$} \\
\hline - Hematologic malignancies & 16 & 1 & 1 \\
\hline - Primary Immunodeficiency Diseases & 6 & 2 & 0 \\
\hline - Other & 1 & 0 & 0 \\
\hline Total-body irradiation & 8 & 1 & 1 \\
\hline Donor/recipient Female/male & 9 & 0 & 0 \\
\hline Cell dose (Mean) & $\begin{array}{l}9 \times 10^{6} / \mathrm{kg} \\
(2.5-14.6)\end{array}$ & $\begin{array}{c}8.8 \times 10^{5} / \mathrm{kg} \\
(4.4-13.3)\end{array}$ & $\begin{array}{c}1.48 \times 10^{6} \\
/ \mathrm{kg}\end{array}$ \\
\hline $\begin{array}{l}\text { Infection } 3 \text { months prior } \\
\text { to allogeneic transplant, } \mathrm{n}\end{array}$ & 7 & 1 & 0 \\
\hline \multicolumn{4}{|c|}{ Donor, $\mathrm{n}$} \\
\hline - HLA-identical related & 14 & 0 & 1 \\
\hline - $\quad$ HLA-matched unrelated & 0 & 3 & 0 \\
\hline - HLA-identical unrelated & 1 & 0 & 0 \\
\hline - Haploidentical & 4 & 0 & 0 \\
\hline Bacteremia within the first 7 days post-transplant, $n$ & 10 & 2 & 0 \\
\hline CMV infection in the recipient $\mathrm{n}$ & 4 & 0 & 0 \\
\hline
\end{tabular}




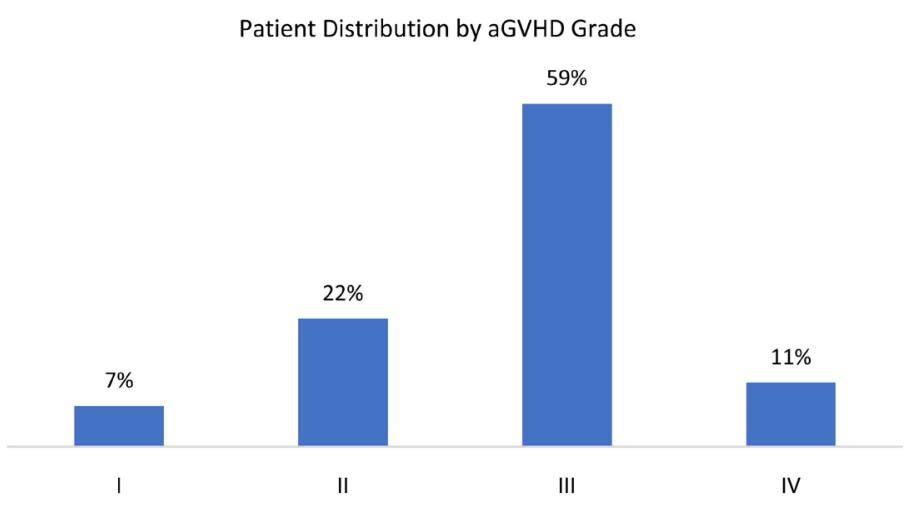

Figure 2. Patient distribution by aGVHD grade.

Table 3. Multivariate analysis adjusted by significant risk factor.

\begin{tabular}{cccc}
\hline Multivariate analysis adjusted by significant risk factor & & \\
\hline Risk Factor & $\begin{array}{c}\text { Patients with aGVHD } \\
\text { and risk factor, } \mathrm{n}\end{array}$ & OR & p-value \\
\hline Peripheral blood & 23 & 11.4 & 0.001 \\
Infection 3 months prior to allogeneic transplant & 8 & 4.5 & 0.03 \\
CMV infection in the recipient & 4 & 4.68 & 0.03 \\
PB $>$ BM & 20 & 16.3 & 0.001 \\
Cell Dose $>8.3 \times 10^{6} / \mathrm{kg}$ & 3 & 4.6 & 0.03 \\
\hline
\end{tabular}

reported incidence. However, the presentation in our institute is in the lower limit, this could be explained on account that most of the allogeneic HSCT procedures were from umbilical cord (53\%), a source that has a lower risk for aGVHD development (OR: 0.15; p < 0.001) [1] [2] [3] [4] [5].

The most commonly reported risk factors are also present in our analysis: peripheral blood $>$ bone marrow (OR 12.3; $\mathrm{p}<0.001)$, cell dose $>8.3 \times 10^{6} / \mathrm{kg}(\mathrm{OR}$ 7.1; $\mathrm{p}=0.05)[4][5]$.

One of the first studies to analyze the associations between infections and aGVHD is the study by Poutsiaka et al., the analysis included 218 patients, in this report it is reported that in the multivariate analysis, the infections that occur at the beginning of the conditioning and the first 10 days are a risk factor for developing aGVHD grade 2 or higher (HR $2.1 \mathrm{p}<0.02)$ [6].

In the most recent report, especially in the pediatric population, Sano et al., conducted a retrospective study with 301 patients, at pediatric age, where report that HLA mismatched donor transplants and early stage blood stream infections (0 to 30days) ( $\mathrm{HR} 4.870, \mathrm{p}<0.001)$ and $(\mathrm{HR}=3.010, \mathrm{p}=0.001)$ respectively, which is why they are considered as a risk factor for the development of aGVHD grades III-IV [3].

In our study, we analyzed the infections that occurred in the patients but with a time of 3 months prior to the procedure to allogeneic HSCT (OR $4.5 p<00.3$ ), and was an important risk factor for aGVHD. In the two previously reported 
studies as in ours, the cause for what is thought is the aGVHD is the activation of the $\mathrm{T}$ cells of the donor by the host antigen presenting cells [6]. Main bacterial infections within the population studied included: $S$. aureus and $P$. aeruginosa.

With respect to CMV infection in the recipient defined by seropositivity or positive viral load, we found that in the univariate (OR $4.11 \mathrm{p}<0.003$ ) and multivariate analysis (OR $4.68 \mathrm{p}<0.03$ ) it is significant and acts in an independent manner for the development of aGVHD, but it is controversial that in the study by Poutsiaka et al., CMV infection has no value as a risk factor and even acts as a reduction factor for aGVHD (HR $0.45 \mathrm{p}<0.008)$ [6].

However, recently Jaing et al., reported in a population of 290 pediatric patients, which had CMV infection, had statistical significance to develop aGVHD grade III and IV in the univariate analysis and is an independent factor in the multivariate (OR $11 \mathrm{p}<0.001$ ), which provides support for our results, since both studies were performed in the pediatric population [2].

Mexico has an emerging market economy that presents a high incidence of infectious diseases that characterize developing nations, those coexist with chronic diseases, characteristic of developed countries. Therefore, approximately $80 \%$ of the adult population has serologic positivity to CMV without developing the disease. However, when the immunity is affected there is a possibility of developing subclinical or clinical manifestations of the disease. Concurrently, within the same epidemiological background, bacterial infections are a frequent cause of morbidity in patients with hematologic disease and immunodeficiency disorders prior to allogeneic HSCT [7].

It is well known that gastrointestinal damage inflicted by the conditioning regimen allows for bacterial products translocation (lipopolysaccharides) that co-stimulate the immune response, acting as a risk factor for development of aGVHD.

The institutional protocol for the recipient, regarding CMV infection, within the required laboratory analysis includes the antigenemia assay for detexting PP65 antigen in polymorphonuclear leukocytes and/or the viral CMV load by RT-PCR (positive > 1000 copies/mL). It has been reported that there is a relationship between the GVHD in the gastrointestinal (GI) tract and CMV GI disease. Cho et al. highlight that the presence of GI symptoms due to CMV infection has to be identified and treated, as CMV GI disease negatively affects GVHD survival [8].

On the other hand, Saadi et al. reported that there are costimulatory molecule gene polymorphisms that relate to aGVHD, including CTLA, CD28, ICOS and PD-1; with a statistically significant association between CD28 $+17 \mathrm{C} / \mathrm{T}$ and CTLA4-1661 A/G genotypes to CMV active infection in allogeneic HSCT patients that developed GVHD, compared to those that not developed GVHD [9] [10]. Still, more studies are warranted to study the validity of these costimulatory gene polymorphisms associations.

Other studies report that CMV infection is associated to immune-mediated diseases that accompany the development of chronic GVHD following allogene- 
ic HSCT. The latter is due to the production of specific antibodies against CD13 during the course of CMV disease [11].

Boström et al. report that seropositive CMV analysis in recipients and donors was a risk factor for developing chronic GVHD [12].

Our study has also limiting, the first is that it is a retrospective study, with patients treated with various conditioning and antimicrobial prophylaxis schemes, and we did not evaluate the patients who had infection from the moment of infusion (day or) and its subsequent evolution, for which it is convenient to carry out a new analysis with a prospective cohort and in a multi-institutional way, since the current report is based on a single institution, another one of the limitations was that we did not evaluate the presence of infections with mortality related to transplantation, as reported in other studies.

\section{Conclusion}

Either bacterial infection or CMV infection in the recipient was significant risk factor within the aGVHD recipients; it is important to consider these factors for patients that are going to receive an allogeneic HSCT.

\section{Acknowledgements}

This research wasn't supported by any foundation or donor. We thank our colleagues from National Institute of Pediatrics (INP) who provided insight and expertise that greatly assisted the research.

\section{Conflicts of Interest}

The study did not have a conflict of interest, all patients undergoing transplantation did so under informed consent and the present study was approved by the institutional research and ethics committees.

\section{References}

[1] Carpenter, P.A. and Macmillan, M.L. (2010) Management of Acute graft-versus-Host Disease in Children. Pediatric Clinics of North America, 57, 273-295.

https://doi.org/10.1016/j.pcl.2009.11.007

[2] Jaing, T.H., Chang, T.Y., Chen, S.H., Wen, Y.C., Yu, T.J., Lee, C.F., Yang, C.P. and Tsay, P.K. (2019) Factors Associated with Cytomegalovirus Infection in Children Undergoing Allogeneic Hematopoietic Stem-Cell Transplantation. Medicine, 98, e14172. https://doi.org/10.1097/MD.0000000000014172

[3] Sano, H., Hilinski, J.A., Qayed, M., Applegate, K., Newton, J.G., Watkins, B., Chiang, K.Y. and Horan, J. (2018) Early Blood Stream Infection Following Allogeneic Hematopoietic Stem Cell Transplantation Is a Risk Factor for Acute Grade III-IV GVHD in Children and Adolescents. Pediatric Blood \& Cancer, 65, 1-6. https://doi.org/10.1002/pbc.26821

[4] Svennilson, J., Remberger, M. and Ringdén, O. (2003) Risk Factors for Moderate-to-Severe Acute Graft-vs.-Host Disease after Allogeneic Stem Cell Transplantation in Children. Pediatric Transplantation, 7, 130-136. https://doi.org/10.1034/j.1399-3046.2003.00030.x 
[5] Flowers, M.E., Inamoto, Y., Carpenter, P.A., Lee, S.J., Kiem, H.P., Petersdorf, E.W., et al. (2011) Comparative Analysis of Risk Factors for Acute Graft-versus-Host Disease and for Chronic Graft-versus-Host Disease according to National Institutes of Health Consensus Criteria. Blood, 117, 3214-3219.

https://doi.org/10.1182/blood-2010-08-302109

[6] Poutsiaka, D.D., Munson, D., Price, L.L., Chan, G.W. and Snydman, D.R. (2011) Blood Stream Infection (BSI) and Acute GVHD after Hematopoietic SCT (HSCT) Are Associated. Bone Marrow Transplantation, 46, 300-307.

https://doi.org/10.1038/bmt.2010.112

[7] Morales-Sánchez, A., Pompa-Mera, E.N. and Fajardo-Gutiérrez, A. (2014) EBV, HCMV, HHV6, and HHV7 Screening in Bone Marrow Samples from Children with Acute Lymphoblastic Leukemia. BioMed Research International, 2014, Article ID: 54809. https://doi.org/10.1155/2014/548097

[8] Cantoni, N., Hirsch, H.H., Khanna, N., Gerull, S., Buser, A., Bucher, C., et al. (2010) Evidence for a Bidirectional Relationship between Cytomegalovirus Replication and Acute Graft-versus-Host Disease. Journal of the American Society for Blood and Marrow Transplantation, 16, 1309-1314. https://doi.org/10.1016/j.bbmt.2010.03.020

[9] Cho, B.S., Yahng, S.A., Kim, J.H., Yoon, J.H., Shin, S.H., Lee, S.E., et al. (2013) Impact of Cytomegalovirus Gastrointestinal Disease on the Clinical Outcomes in Patients with Gastrointestinal Graft-versus-Host Disease in the Era of Preemptive Therapy. Annals of Hematology, 92, 497-504. https://doi.org/10.1007/s00277-012-1632-x

[10] Saadi, M.I., Yaghobi, R., Karimi, M.H., Geramizadeh, B., Ramzi, M. and Zakerinia, M. (2013) Association of the Costimulatory Molecule Gene Polymorphisms and Active Cytomegalovirus Infection in Hematopoietic Stem Cell Transplant Patients. Molecular Biology Reports, 40, 5833-5842. https://doi.org/10.1007/s11033-013-2689-x

[11] Soderberg, C., Larsson, S., Rozell, B.L., Sumitran-Karuppan, S., Ljungman, P. and Moller, E. (1996) Cytomegalovirus-Induced CD13-Specific Autoimmunity-A Possible Cause of Chronic Graft-vs-Host Disease. Transplantation, 61, 600-609. https://doi.org/10.1097/00007890-199602270-00015

[12] Boström, L., Ringdén, O., Jacobsen, N., Zwaan, F. and Nilsson, B. (1990) A European Multicenter Study of Chronic Graft-versus-Host Disease. The Role of Cytomegalovirus Serology in Recipients and Donors-Acute Graft-versus-Host Disease, and Splenectomy. Transplantation, 49, 1100-1105.

https://doi.org/10.1097/00007890-199006000-00014 